\title{
O PEQUENO PRÍNCIPE: UMA ANÁLISE MULTIMODAL DAS OBRAS LITERÁRIA E CINEMATOGRÁFICA ${ }^{1}$
}

\author{
The Little Prince: A multimodal analysis of the literary and \\ cinematographic works
}

\author{
Lilian Regina Gobbi BACHI \\ Programa de Pós-Graduação em Letras \\ Universidade Estadual de Maringá \\ lilianbachi@outlook.com \\ https://orcid.org/0000-0002-7155-7899
}

\begin{abstract}
RESUMO: Esse artigo, tendo como corpus as obras literária e cinematográfica $O$ Pequeno Príncipe, busca responder como as múltiplas semioses se articulam na sintaxe visual estabelecendo coerência na construção das narrativas. Nosso objetivo geral é explorar os sistemas semióticos verbal e visual e as suas relações. Os objetivos específicos são: i) perceber quais são os recursos semióticos utilizados no corpus de pesquisa; ii) analisar a localização das entidades no espaço para identificar quais são suas implicações na produção de significados; iii) analisar como os sistemas semióticos são traduzidos de um sistema para o outro como processos sociais. Tomaremos como base teórica principalmente os estudos Kress e van Leeuwen (2006) e de Iedema (2001). Nossa análise aponta que os recursos semióticos usados na construção da narrativa fílmica representam e reafirmam o discurso verbal que conduz a obra literária $O$ pequeno Príncipe, corroborando para a coerência na construção das narrativas. PALAVRAS-CHAVE: O Pequeno Príncipe; Literatura; Cinema; Multimodalidade.
\end{abstract}

\begin{abstract}
This article has, as scientific corpus, the literary and cinematographic works of The Little Prince, and it seeks to answer how the multiple semiosis are articulated in the visual syntax, establishing coherence in the construction of the narratives. Our overall objective is to explore the verbal and visual semiotic systems as well as their relations. The specific objectives are: i) to apprehend which semiotic resources are used in the research corpus; ii) to analyze the spatial loca-
\end{abstract}

\footnotetext{
${ }^{1}$ Este artigo é um recorte dos resultados obtidos da pesquisa de Mestrado em Letras cujo título é "Uma análise textual de o Pequeno Príncipe: as visões sobre a infância no livro de Saint-Exupèry e no filme de Osborne".
}

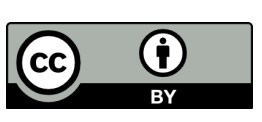


tion of the entities in order to identify their underlying implications in the production of meaning; iii) to analyze how the semiotic systems are translated from one system to another as a social process. We will take as our theoretical basis mainly the studies of Kress and van Leeuwen (2006) and of Iedema (2001). Our analysis points out that the semiotic resources used in the construction of the film narrative represent and reaffirm the verbal discourse that leads the literary work The Little Prince, corroborating the coherence in the construction of the narratives. KEYWORDS: The Little Prince; Literature; Film; Multimodality.

\section{INTRODUÇÃO}

Há mais de um século o cinema vem representando histórias literárias. Essa nova cultura se deu especialmente pela necessidade daqueles que desejavam consumir romances de maneira mais dinâmica e rápida (BACHI, 2020). Nesse sentido, é possível dizer que hoje, com a expansão cada vez mais extensa da sociedade globalizada, os diferentes modos de representação são também desdobramentos dessa sociedade, que se preocupa tanto com a conectividade entre as infinitas comunidades e culturas quanto com a conectividade entre as múltiplas linguagens e semioses.

Diante dessa nova realidade, o estudo das multimodalidades se faz necessário para compreendermos como se dá o processo de transformação de elementos verbais (literários) em elementos semióticos (cinematográficos). É inegável que as novas tecnologias virtuais permitem maneiras diferentes de acessar informações, bem como novas formas de raciocinar e de adquirir conhecimento. Desse modo, podemos dizer que "a moderna mídia 'literatura' ensina seus leitores a imaginar não mais apenas significações textuais, mas também a presença do uso desses textos”, o que significa compreender que o texto literário não é composto de forma estanque apenas pela linguagem verbal, mas vai além constituindo-se de vários modos e meios semióticos, sejam imagens, cores, gestos ou sons, o que o torna "uma mídia aplicada em seu contexto de uso" (SIERAKOWSKI, 2012, p. 52).

Não se pode deixar de lembrar que considerar o texto em seu contexto de uso é um princípio básico, no entanto a identificação de categorias que permitem a segmentação das imagens em movimento, como é o caso do texto cinematográfico, tem sido uma prática nova nos estudos semióticos. Investigações detalhadas têm sido empreendidas visando a descrever recursos semióticos, funções e sistemas de múltiplos modos, a fim de organizar seus princípios e investigar suas referências culturais. 
No que diz respeito principalmente às adaptações de textos literários para o cinema, uma das questões problemáticas, tanto no uso dos conceitos elaborados para o domínio literário quanto na recepção dos textos, é a falta de fidelidade entre as obras adaptadas e o texto literário de origem. A produção final para o cinema desperta questionamentos sobre as escolhas feitas pelos adaptadores, ao serem feitas modificações em objetos e personagens presentes na narrativa. Felizmente, os trabalhos mais recentes quanto aos estudos da adaptação, como os de Plaza (2008) que trabalha com a tradução intersemiótica ou de Stam (2000) que trata das teorias de adaptação da literatura para o cinema, têm buscado por um ponto de vista que considere e respeite as condições de produção envolvidas na criação cinematográfica, a saber: o contexto sociocultural e histórico, a linguagem, a montagem, a fotografia, o som, a cenografia e o ponto de vista narrativo, elementos responsáveis pela construção de sentidos e atualização de temas no sistema semiótico compreendido pelo cinema.

Quando associamos narrativa e multimodalidade, o uso de diversos modos numa mesma obra ganha destaque na literatura infantil, sobretudo a partir dos anos 1960, marco do surgimento do livro ilustrado moderno, um tipo de literatura cuja articulação entre imagem e texto é condição indispensável para a compreensão da história.

Nos livros ilustrados, a leitura vai além da compreensão do texto verbal, é preciso que o leitor domine outros elementos semióticos para interagir com a obra. Nesse sentido, na contemporaneidade, a literatura enquanto cinema - ou outras produções audiovisuais, a exemplo das séries - desafia critérios historicamente estabelecidos e produz "significados mediante uma sintaxe visual", o que caracteriza a necessidade de existência de uma "gramática que exige um nível de leitura crítico", isto é, "um leitor capaz de ler imagens" (SANTOS, 2016, p. 19). A despeito disso, esta forma de literatura é uma realidade, disponível a todos, em produções de diferentes gêneros que lançam mão de recursos multimodais cada dia mais sofisticados, acrescentando ao texto sons, cores, imagens em movimento e interatividade.

Inegavelmente, com o avanço das tecnologias, as práticas sociais deram novas configurações linguísticas às formas de comunicação dando ênfase aos textos multimodais utilizados largamente em diferentes esferas. Sem dúvidas, o texto multimodal fica cada vez mais em evidência com a globalização que faz efervescer as transformações socioculturais onde se comunica cada vez mais por meio de textos imagéticos ou multimodais carregados de múltiplos sentidos. 
Assim, a necessidade de conferir atenção aos significados visuais na sua relação com os significados linguísticos expressos nos textos multimodais são requisitos fundamentais de forma a desenvolver competências críticas de leitura dos textos.

Este artigo aborda, portanto, a imagem cinematográfica - o filme $O$ Pequeno Príncipe - como uma das formas de circulação do texto literário de mesmo nome, lançado em 1943 por Antoine Saint Exupéry. Considera-a um novo modo de representação e também uma forma de interligar dois sistemas de signos diferentes - o texto e a imagem - de modo que o visual e o verbal se apresentem em uma relação dialógica. Diante disso, é essencial que os conceitos de Multimodalidade (Iedema, 2001) e de Gramática Visual (Kress e van Leeuwen, 2006) sejam brevemente discutidos, bem como as noções de texto cinematográfico e de leitura de textos em movimento.

Assim, este artigo tem como corpus as obras literária e cinematográfica O Pequeno Príncipe, de Antoine Saint Exupéry (1943) e de Mark Osborne (2015), respectivamente. O objetivo geral é explorar os sistemas semióticos verbal e visual e as suas relações. Os objetivos específicos são: i) perceber quais são os recursos semióticos utilizados no corpus de pesquisa; ii) analisar a localização das entidades no espaço para identificar quais são suas implicações na produção de significados; iii) analisar como os sistemas semióticos são traduzidos de um sistema para o outro como processos sociais. Com isso, espero chegar à questão que organiza esta análise, a saber: Como as múltiplas semioses se articulam na sintaxe visual estabelecendo coerência na construção das narrativas?

Desse modo, o presente trabalho está divido em duas seções: a primeira seção será reservada à revisão da literatura, na segunda seção apresentarei a análise do corpus e discussão dos resultados.

A escolha dos recortes que serão analisados se deu a partir da identificação da função da Tomada na Cena e no texto em geral, conforme sugere Hendges e Nascimento (2016). As Sequências foram selecionadas considerando suas continuidades temáticas e lógicas. Tais escolhas buscam responder aos objetivos dessa pesquisa.

\section{REVISÃO DA LITERATURA}

O termo multimodalidade surgiu da necessidade de situar as diferentes formas de representação. De acordo com Iedema (2003), é necessário considerar que língua e imagem são complementares e mais ainda que as múltiplas semioses, mais do que funcionarem como modo de comunicação, são meios de expressão. Nesse sentido, considerar a multimodalidade significa compreender que a produção textual não é 
composta de forma estanque apenas pela linguagem verbal, mas vai além constituindo-se de vários modos e meios semióticos, sejam imagens, cores, gestos ou sons.

Holanda (2012) explica que

as imagens desempenham papeis antes exercidos pela linguagem, de forma que o jeito de entender textos multimodais consiste na análise dos modos representacionais por meio dos quais os textos são produzidos e os recursos semióticos para a produção de significados entendidos. Isso remete ao potencial da multimodalidade que vai desde a descrição dos recursos semióticos para a produção de relações semióticas incluída a interação mediada pelo significado, às inter-relações com a tecnologia (HOLANDA, 2012, p.134).

Pensando nisso, Kress e van Leeuwen (2006), extrapolando o foco da Linguística Sistêmico-Funcional de Halliday, formularam a Gramática Visual (GV), que surge da necessidade que esses autores tinham em desenvolver um método de análise que fosse capaz de verificar como todos os recursos semióticos presentes em um texto constroem significados sociais. A GV tem por objetivo descrever o modo como elementos visuais, que são culturalmente associados a valores e funções, são organizados em orações visuais de maneira que produzam sentidos vários (HENDGES e NASCIMENTO, 2016, p. 27 apud KRESS; VAN LEEUWEN, 2006, p. 1).

A partir de seus estudos sobre a Teoria Semiótica, Kress (2003) afirma que as cores, do mesmo modo que qualquer outra semiose, podem materializar discursos que refletem a realidade, articulando valores e conhecimentos próprios de uma cultura. Moraes (2015) aponta que os significados que são produzidos pelas cores "são articulados em uma cultura e refletem uma produção social, cultural e histórica” (p. 241). Ainda, a mesma autora afirma que a cor, como qualquer outro modo, não substitui o texto escrito e nem é substituído por ele, de acordo com Moraes (2015), “a relação com a cor é cultural, experiencial, mas é também fisiológica, biológica e ativa certos estados emocionais".

Além disso, a perspectiva multimodal leva em conta a influência do meio na produção de sentidos, bem como o contexto de produção textual, o que significa dizer que a análise de textos multimodais é diretamente dependente do contexto. Todos esses elementos são importantes na constituição de significados de um texto multimodal. Por isso, os estudos multimodais objetivam entender esses processos de produção de sentidos situados socialmente e, também, oferecer recursos para descrever uma prática ou representação em toda a sua especificidade semiótica.

Nesse sentido, a gramática de Kress e van Leeuwen sugere uma estrutura que descreva também as características linguísticas/gramaticais inerentes às imagens, isto é, Revista X, v. 16, n. 6, p. 1742-1766, 2021. 
os sintagmas. Isso orienta para a leitura da imagem como produtora de significados e para a compreensão de como a linguagem visual se organiza em suas diferentes condições de uso. Santos (2016) afirma que as modalidades visual e imagética produzem "significados mediante uma sintaxe visual", o que, para o autor, caracteriza a necessidade de existência de uma "gramática que exige um nível de leitura crítico", isto é, "um leitor capaz de ler imagens" (p. 19).

Holanda (2012) explica que assim como a "gramática da língua se realiza por meio da combinação entre palavras, frases, orações e textos", a "gramática visual (GDV) explora os modos como os elementos - pessoas, coisas e lugares - são representados, observando o grau de extensão dessa representação visual” (p. 135).

Kress (2003) afirma que, embora a multimodalidade possa identificar os modos, só a Teoria Semiótica Social é capaz de apontar para os significados em todas as suas instâncias. De acordo com esse autor, para se analisar os significados é necessário considerar as interações sociais, a troca de significados em cada cultura, os modos e os meios de veiculação.

É preciso anotar que a própria sociedade é multimodal, uma vez que combina diferentes recursos linguísticos para se comunicar, construindo, portanto, sentidos. Assim, citando Jewitt (2009), Carvalho (2010) assinala quatro suportes teóricos nos quais se assentam a abordagem multimodal, a saber:

A primeira suposição básica é a de que os significados são produzidos, distribuídos, recebidos, interpretados e reproduzidos através de uma série de modos comunicativos e representacionais [...]. A segunda suposição defende que todos os modos semióticos, para além da fala e da escrita, são moldados através dos seus usos culturais, históricos e sociais, a fim de realizarem diferentes trabalhos comunicativos. A terceira suposição remete ao fato de que as pessoas regem significados através da seleção e da configuração de diferentes modos [...]. A quarta suposição, por sua vez, sublinha que os significados dos signos realizados pelos modos semióticos são sociais (JWITT, 2009 apud CARVALHO, 2010, p. 266).

Assim, a GV permite que o autor/leitor faça uso de qualidades lexicais (cores, saturação, nitidez), qualidades sintáticas (aparência e movimento), qualidades semânticas (objetos representados explicitamente ou apenas sugeridos, que podem ser interpretados), e qualidades pragmáticas (função e utilidade da imagem) com a finalidade de constituir interpretações socialmente significativas (ALMEIDA, 2012, p. 44). 
$\mathrm{Na} \mathrm{GV}$, os teóricos procuram por regularidades que permitam compreender como a representação visual e as diferentes relações levam a uma leitura específica. Nesse sentido, a escolha feita pelo autor em posicionar determinado objeto possibilita um potencial de significações e caminhos de leitura (VIEIRA, 2015, p. 117). Desse modo, a noção de escolha é fundamental, já que

Todos os elementos provenientes de sistemas semióticos diversos que ocorrem na construção de um texto multimodal podem ser analisados, relacionados uns com os outros e interpretados em termos das escolhas feitas entre os recursos semióticos disponíveis e em termos das suas contribuições para a função social e comunicativa do texto (VIEIRA, 2015, p. 117).

Vale ressaltar que, considerando a definição de Kress (1995, p. 7) para o termo multimodalidade, a tradução intersemiótica, como é o caso da literatura para o cinema, é compreendida aqui como multimodalidade.

Inegavelmente, asadaptaçõesmais recorrentesnaatualidadesãoascinematográficas, uma vez que a literatura é um terreno fértil de informações que podem passar do contar para o mostrar (HUTCHEON, 2006, apud SIERAKOWSKI, 2012, p. 57). De acordo com Sierakowski (2012, p. 59), ao citar Hutcheon (2006), no processo de adaptação o autor precisa "atualizar ou concretizar ideias; tem de fazer seleções simplificadas, mas também podem ampliar ou extrapolar; tem de fazer analogias; eles criticam ou mostram seu respeito, etc" (HUTCHEON, 2006, p.3 apud SIERAKOWSKI, 2012, p. 57).

Sem dúvida, uma das questões problemáticas nas adaptações, tanto no uso dos conceitos elaborados para o domínio literário quanto na recepção dos textos, diz respeito à falta de fidelidade entre as obras adaptadas e o texto literário de origem, no entanto é preciso considerar que essa tradução de um meio para o outro está sujeita às regras de funcionamento particulares de cada meio. Nesse sentido, é válido ao analista indagar as razões pelas quais o texto adquire determinado formato na nova mídia/meio. Kress e van Leeuwen (2006) apontam para o fato de que em uma adaptação tende-se a uma tentativa de fidelidade ao texto fonte, mas que, considerando o novo contexto e as particularidades de cada meio, a transformação é necessária.

Em se tratando, portanto, da análise de textos multimodais, mais especificamente de texto cinematográfico, Hendges e Nascimento (2016), a partir da leitura das propostas de Iedema, 2001; O’Halloran, 2004; articulam quatro categorias para a análise de imagens em movimento: Quadro, Tomada, Cena e Sequência. 
De acordo com Iedema (2001, p. 189), o Quadro é "uma imagem congelada de uma tomada". Hendges e Nascimento (2016, p. 32) explicam que o Quadro "funciona como uma 'fotografia marcante' e representativa do conteúdo dessa Tomada”. Em um movimento de análise, é possível que o analista tire várias fotografias que representem o conjunto de sentidos de uma Tomada, desse modo uma Tomada é dividida em vários Quadros representativos. Segundo Hendges e Nascimento (2016), o que diferencia o Quadro da Tomada é que o primeiro exclui movimentos, áudio e efeitos sonoros, apagando, assim, os sentidos que esses elementos podem produzir, dessa maneira "parcelar imagens em movimento na forma de Quadros significa eliminar o fluxo de movimento e a progressão da experiência representada na Tomada” (p. 32).

Na perspectiva de Halliday e Matthiessen (2004), os Quadros produzem três tipos de significados: ideacional, interpessoal e textual, o que podemos comparar às metafunções da GV de Kress e van Leeuwen: ideacional, representacional e composicional.

Um possível caminho para a escolha de um Quadro, de acordo com Hendges e Nascimento (2016), é “identificar a função da Tomada na Cena e no texto em geral” (p. 33).

As Tomadas, por sua vez, são definidas por Iedema (2001, p. 189) como "ações de câmeras desprovidas de cortes". O'Halloran (2004) assevera que a Tomada é "tudo o que é visualizado em uma gravação na medida em que ela se desdobra ao longo do tempo juntamente com a trilha sonora" (HENDGES e NASCIMENTO, 2016, p. 35 apud O'HALLORAN, 2004, p.117).

Iedema (2001) define Cena como "uma filmagem em "um único espaço-tempo, mas constituída de mais de uma Tomada"” (IEDEMA, 2001, p. 189, apud HENDGES e NASCIMENTO, 2016, p. 38). Desse modo, a Cena é definida pelo cenário, se há mudança de cenário, logo temos uma nova Cena, é a partir do grau de continuidade ou não do espaço e tempo que se define se há mudança de Tomada.

De acordo com Iedema (2001), a Sequência é definida como unidades que possuem "múltiplos espaço-tempo". Diferente da Cena, o que define uma Sequência, na análise de imagens em movimento, é sua continuidade temática ou lógica. Hendges e Nascimento (2016, p. 40) explicam que para se identificar uma Sequência "é necessário um conjunto possível de relações temáticas e lógicas".

Retomando a perspectiva de Halliday e Matthiessen (2004), em relação aos significados produzidos pelos Quadros (ideacional, interpessoal e textual) e às metafunções da GV de Kress e van Leeuwen (ideacional, representacional e composicional), é importante ressaltar que o objetivo dessa pesquisa é tratar da coerência na construção 
das narrativas que formam o corpus, a partir da sintaxe visual articulada pelas múltiplas semioses, isso implica ter como foco de análise a metafunção composicional.

No entanto, como explica Kress e van Leeuwen (2006, p. 181), os significados gerados pela metafunção composicional se referem "à composição do todo, ao modo em que os elementos representacionais e interativos se relacionam entre si, ao modo que eles são integrados em um todo significativo", o que significa dizer que a organização textual, seja ela verbal ou visual, confere ao texto valores e sentidos específicos.

Não nos interessa nesse artigo tratar sobre a interação entre os participantes da estrutura textual e o receptor, por isso nos debruçaremos sobre os conceitos de metafunção representacional e composicional, mais especificamente sobre o último. Os significados produzidos pela metafunção representacional apontam para a relação que existe entre os participantes de uma estrutura visual (sejam eles objetos ou seres), tendo em vista que cada um desses participantes cumpre um papel funcional no contexto da imagem e são, portanto, identificados por esse papel.

Kress e van Leeuwen (2006) explicam que os processos representacionais podem ser dois: narrativo ou conceitual. Por uma questão de escolha analítica, trataremos, nesse artigo, do segundo que, de acordo com os mesmos autores, são divididos em classificacional, analítico e simbólico. Nessa análise nos interessa os processos simbólicos.

Kress e van Leeuwen (2006, p. 79) explicam que algumas imagens podem descrever processos simbólicos divididos em duas estruturas: atributos simbólicos e atributos sugestivos, e apontam que os participantes conceituais de um ato semiótico "representam os participantes em termos de sua essência mais ou menos generalizada, instável e infinita, em termos de classe, ou estrutura, ou significados".

Os autores asseveram ainda que o atributo simbólico tem como característica essencial a presença de elementos colocados em primeiro plano de modo muito detalhado (com cores, iluminação, tons muito presentes). Esse atributo tem relação direta com valores simbólicos.

Voltando à metafunção composicional, é preciso explicar que Kress e van Leeuwen (2006) a organizam através de três recursos: valor da informação, enquadramento e saliência.

$\mathrm{O}$ valor de informação diz respeito ao posicionamento dos elementos em uma imagem, o valor pode ser considerado como Dado e Novo, Ideal e Real e Centro e Margem. Conforme explicam os autores, à direita ficam os elementos novos, aquilo que o leitor/espectador ainda não conhece, do lado esquerdo o Dado, isto é, aquilo que já é esperado e conhecido pelo leitor/espectador. Na organização vertical da imagem, na parte 
superior aparecem os elementos apresentados como Ideais, a parte superior, por isso, tende a ser mais emotiva, enquanto na parte inferior são apresentados os elementos Reais, e por isso essa parte do texto tende a ser mais prática e informativa. A organização Centro e Margem apresenta o Centro como o núcleo da informação, enquanto os elementos da margem são apresentados como subservientes e, portanto, marginais. É preciso pontuar que esta ordem não é restrita à linguagem verbal, uma vez que a linguagem visual também segue esta direção, conforme explica Vieira (2015, p. 68).

Nesse sentido, é impossível ignorar os contextos e as práticas sociais, já que as orientações direita, esquerda, em cima, em baixo, centro, margem, nos são conhecidas, mas a aquisição e interiorização da noção de valores constitui extensões metafóricas semiotizadas nos diferentes sistemas semióticos e são determinadas culturalmente.

Outro recurso usado na organização da estrutura composicional é a saliência, que tem por fim criar uma "hierarquia de importância entre os elementos" (KRESS e VAN LEEUWEN, 2006, p. 212). A saliência é o aspecto mais visível ao primeiro olhar, é vista em primeiro plano e participa ativamente da construção da sintaxe visual, funciona como ponto de partida para associações secundárias com outros componentes e pode ser construída por cores, ícones, letras, imagens, posição do texto verbal e plano de fundo.

O terceiro elemento que pode ser usado na organização composicional é o enquadramento, que pode ser realizado de diferentes formas: pelo enquadre ao redor dos elementos, pela descontinuidade de cores, ou pelo espaço vazio entre os elementos, indicando se os elementos de uma composição estão conectados ou não. De acordo com Vieira (2015),

enquadramento busca estudar o direcionamento do foco da lente ao
captar a imagem que pode tanto ser dado pela saliência quanto pelo
jogo de sombra e luz ou ainda pela captação do ângulo do olhar dos
atores representados no texto visual, pois o elemento que antecede deve
se combinar com o que sucede, estabelecendo uma relação contínua de
construção de significado (VIEIRA, 2015, p. 68).

Nesse sentido, é evidente que nenhum modo semiótico deve ser visto de forma isolada, uma vez que só há sentido a partir de suas associações.

O estudo a partir das metafunções permite a investigação do modo como as diferentes semioses se associam na sintaxe visual, a fim de revelar as ideologias e as relações de poder escondidas nas diversas posições ocupadas pelos elementos semióticos na composição multimodal (VIEIRA, 2015, p. 66). 
É preciso pontuar que diferente da escrita, a sintaxe visual articula-se tanto por processos associativos ou metafóricos quanto por padrões metonímicos, que estabelecem relações de sentido a partir da posição de proximidade das imagens. É importante asseverar também que o espaço comunica, assim a organização espacial é uma escolha que o autor faz em virtude dos sentidos que deseja produzir.

\section{ANÁLISE E DISCUSSÃO DOS RESULTADOS}

É interessante pensar no contexto social em que as duas obras que constituem o corpus dessa pesquisa se inserem. A obra literária do francês Antoine Saint Exupéry, lançada em 1943, foi escrita e ilustrada pelo ex-piloto aéreo ao longo da Segunda Guerra Mundial, período em que o aviador foi exilado nos Estados Unidos. Imagina-se que a obra seja fruto das experiências do autor no deserto do Saara, descritas com detalhes em seu livro Terre des hommes (1939).

Já o filme estrelado no cinema em 2015 foi dirigido pelo norte americano Mark Osborne. $\mathrm{O}$ autor adaptador inspirou-se nos temas presentes na obra de Exupéry, a partir da qual reconta os episódios com uma linguagem visual contemporânea, o que implica representar uma nova realidade, já que a adaptação se insere em um contexto social diferente. Por isso, Osborne mostra em sua obra uma personagem atualizada, que representa o cotidiano de uma menina de aproximadamente sete anos que precisa desde já se preparar para a vida adulta, exatamente como ocorre com as crianças na contemporaneidade.

É considerando essas duas condições de produção que essa pesquisa se desenvolve, já que, conforme aponta Moraes (2015), os significados que são produzidos por diferentes modos semióticos "são articulados em uma cultura e refletem uma produção social, cultural e histórica" (p. 241).

Retomando a afirmação de Halliday e Matthiessen (2004) de que o texto é qualquer modo de expressão da linguagem em seu uso e inserido num contexto, podemos afirmar que o corpus aqui analisado são textos, já que têm por finalidade a comunicação a partir de recursos simbólicos.

Diante disso, nosso primeiro movimento de análise é identificar quais são os recursos semióticos utilizados no texto cinematográfico para apresentar a linguagem verbal literária.

Considerando que o texto fílmico não se trata de uma transposição fiel da obra literária, como bem assevera Sierakowski (2012), é preciso pensar nas escolhas do adaptador ao buscar representar elementos da obra de origem. Nesse sentido, levamos em 
conta aquilo que Kress e van Leewven (2006) afirmam sobre os processos simbólicos, mais especificamente sobre o atribuo simbólico, ou seja, o fato de que os elementos que são colocados em primeiro plano têm relação direta com os valores simbólicos que o autor deseja evidenciar.

A seguir, apresentamos recortes selecionados da adaptação fílmica, para logo depois analisá-los:

Quadro 1: Atributos Simbólicos no filme O Pequeno Príncipe.

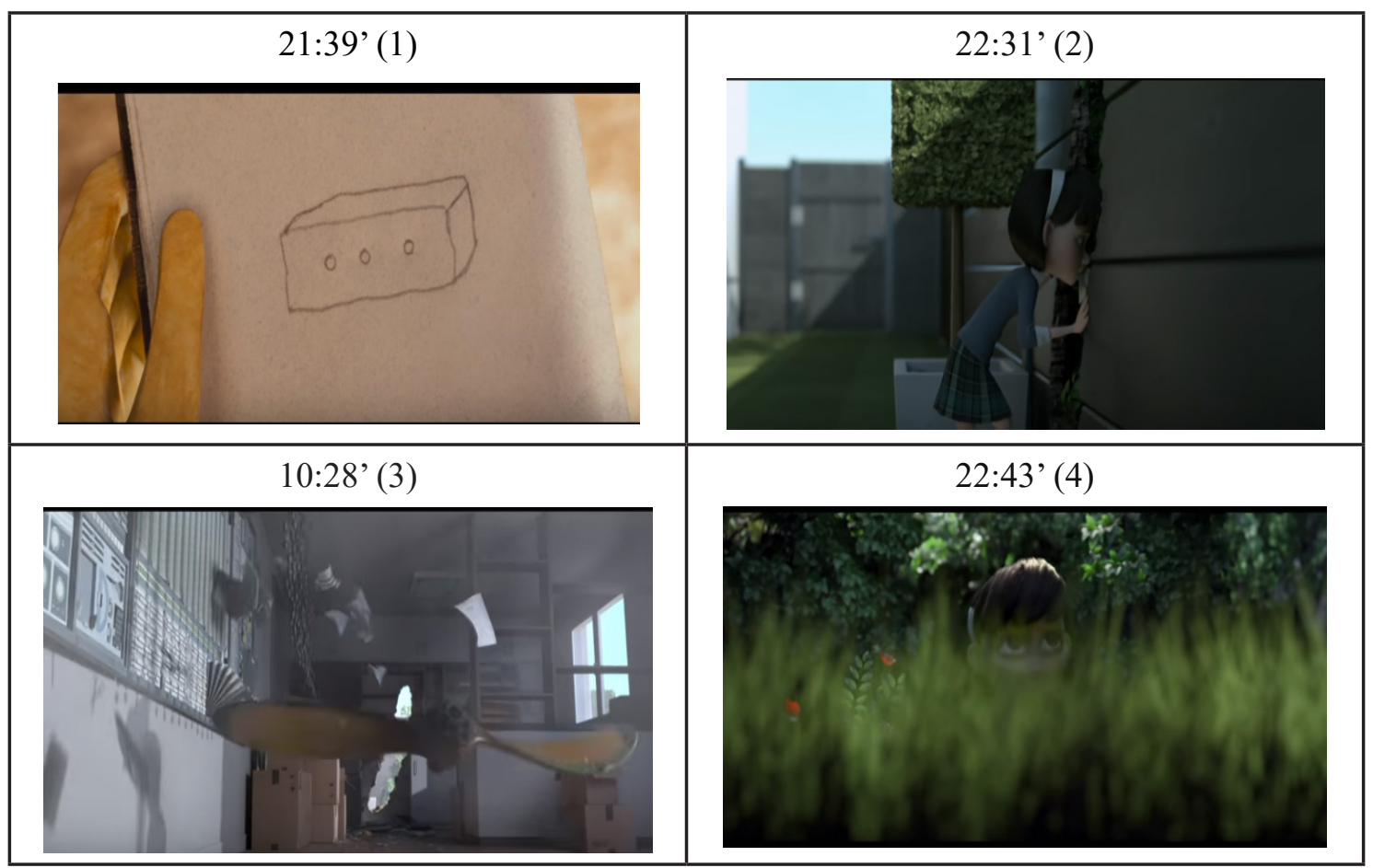

Fonte: Adaptação cinematográfica O Pequeno Príncipe (2015).

Diante dos recortes apresentados, o que fica evidente é que o autor adaptador fez uso de diferentes modos, como cores, iluminação, tom e imagens para representar ora literalmente o que o texto verbal narra, como é o caso do diálogo entre o narrador e o Pequeno Príncipe sobre o desenho do carneiro (1), ora aquilo que representa a essência dos participantes, como é o caso do trecho "Vivi, portanto, só, sem alguém com quem pudesse realmente conversar, até o dia em que uma pane obrigou-me a fazer um pouso de emergência no deserto do Saara" (p. 11), que pode ser associado às Cenas em que a hélice do avião do idoso se solta, provocando um acidente que marca a ruptura entre a vida solitária da menina e sua amizade com o vizinho. 
Chamamos a atenção nesses Quadros para as cores e para a iluminação usadas pelo autor adaptador. Considerando a afirmação de Juwitt (2009) de que "os significados são produzidos, distribuídos, recebidos, interpretados e reproduzidos através de uma série de modos comunicativos e representacionais [...]", consideramos que os recursos semióticos utilizados aqui direcionam o leitor para uma leitura determinada, tendo em vista que "tais significados são influenciados pelos interesses e motivações do produtor do signo em um contexto social específico, que seleciona, adapta e reformula significados através de um processo contínuo de leitura/interpretação do signo" (JWITT, 2009 apud CARVALHO, 2010, p. 266).

O que queremos dizer é que as cores e a iluminação cooperam para a interpretação do sentido de ruptura entre a vida da menina antes do acidente e depois do acidente, pois, como mostram as imagens, há uma mudança nesses aspectos a partir da Cena 22:43'(4), em que ao atravessar o muro da sua casa para a casa do vizinho a menina ganha iluminação e as cores relacionadas a ela deixam de ter um tom acinzentado e passam a ser vivas, o que mais tarde vai contribuir com a coerência na construção das narrativas.

Também na obra literária esse elemento conduz a leitura e interpretação, uma vez que Exupéry faz uso de cores ao representar passagens em que o protagonista se sente feliz e retrata os episódios de tristeza em preto e branco, conforme Quadro 2.

Quadro 2: Atributos simbólicos na obra literária $O$ Pequeno Príncipe.

Assim eu comecei a compreender, pouco
a pouco, meu pequeno principezinho,
a tua vidinha melancólica. Muito
tempo não tiveste outra distração que a
doçura do pôr-do-sol (p.10).

Fonte: O Pequeno Príncipe (2015). 
Com relação à localização das entidades no espaço, procuramos relacioná-las de acordo com suas relações temáticas e lógicas, assim, o que apresentamos a seguir é uma Sequência - e chamamos de Sequência, pois atende à definição desse conceito conforme apontado por Hendges e Nascimento (2016, p. 40) - que busca representar imageticamente o possível significado que Exupéry deseja dar a seu texto quando diz que "só se vê bem com o coração. O essencial é invisível aos olhos" (p. 70).

Quadro 3: Sequências do filme $O$ Pequeno Príncipe.

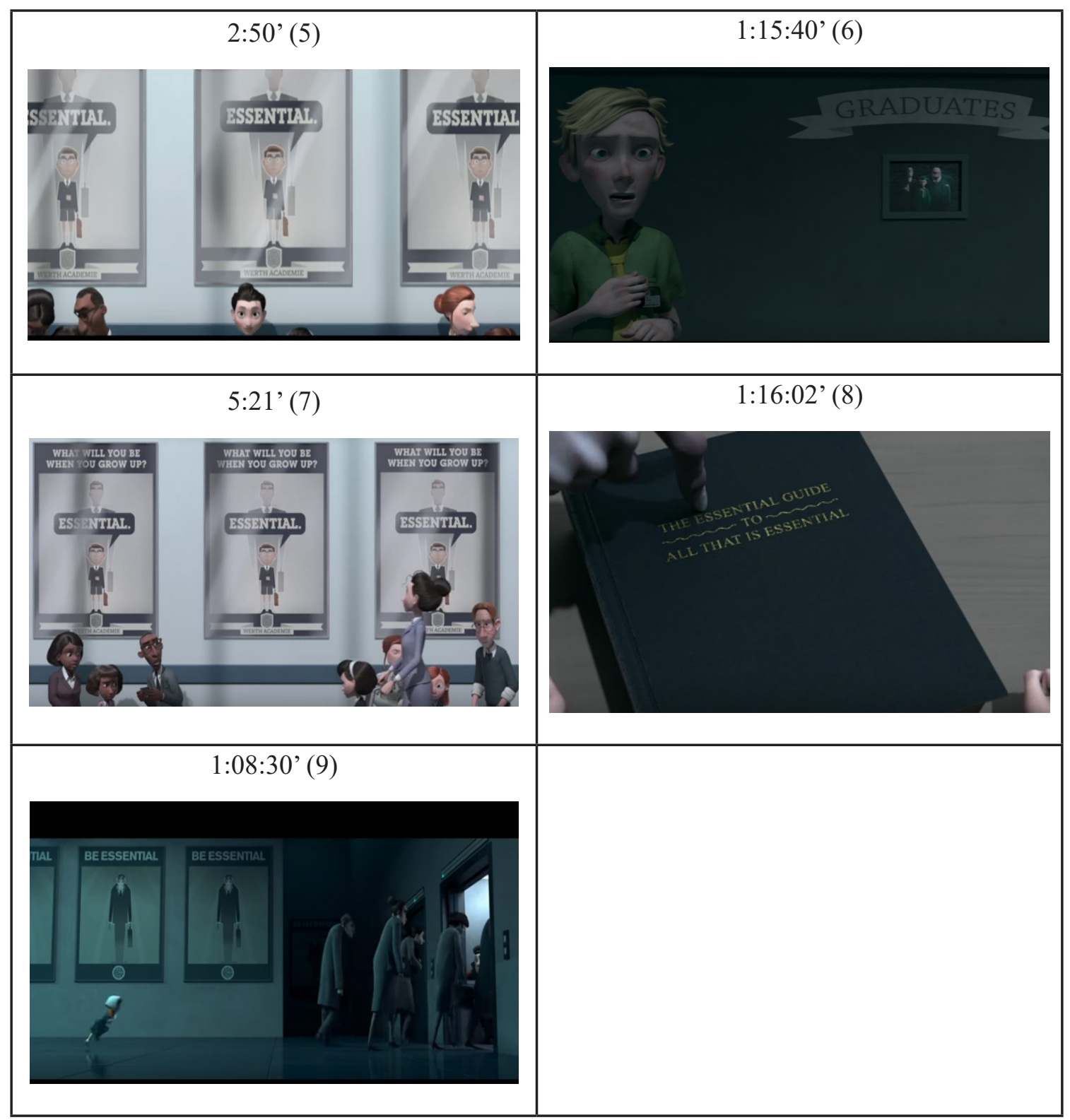

Fonte: Adaptação cinematográfica $O$ Pequeno Príncipe (2015). 
Nas quatro primeiras Sequências em que a palavra "essencial" aparece, ela é colocada em primeiro plano, de modo a chamar a atenção do leitor/espectador. Nas três primeiras ocorrências, o valor de informação desse elemento é apresentado como Ideal, pois encontra-se na parte superior da imagem, dando o sentido de que o Ideal está diretamente relacionado com a conquista acadêmica, no caso da personagem protagonista.

Interessante observar o movimento da câmera nas três primeiras sequências: na primeira (5), a câmera faz um movimento de cima para baixo, deixando claro que o "essencial" é a questão mais importante nesse momento. Na Sequência (7), a câmera filma a menina saindo da sala de avaliação após ser reprovada no teste para ingressar na Werth Academie, num movimento da esquerda para a direita, em que as fotografias penduradas na parede, as quais representam o "essencial”, são representadas como Dado (à esquerda) e a menina como o Novo (à direita), produzindo o significado de que o que é essencial já é conhecido do leitor/espectador, mas a reprovação da menina, que estava muito bem preparada pela mãe para a avaliação, é uma informação nova, já que não se esperava isso.

Na Sequência (9), o que ocorre é o inverso, dessa vez a menina aparece como um elemento Dado (à esquerda) e os quadros na parede como elemento Novo (à direita). A partir desse momento da narrativa, a ideia de essencial tomada no início do texto cinematográfico passa a ser abandonada e o filme passa a convergir com o texto literário.

$\mathrm{Na}$ Sequência seguinte, (6), o quadro com a fotografia já não aparece mais em primeiro plano, ficando quase invisível aos olhos do leitor/espectador, dando lugar à imagem opaca do Sr. Príncipe. Nesse Quadro, a personagem aparece como elemento Dado (à esquerda) e a fotografia como elemento Novo (à direita), dando o sentido de que o "essencial” já não é mais ter um título da academia.

No último Quadro da Sequência (8), aparece em primeiro plano um livro preto com o título The essential Guide To All that essential. Considerando aqui os recursos cores e iluminação, e tendo em vista que, conforme afirma Moraes (2015, p. 241), os significados que são produzidos pelas cores "são articulados em uma cultura e refletem uma produção social, cultural e histórica", e levando em conta o contexto de produção da adaptação cinematográfica, que conforme já mencionamos acontece nos EUA no ano de 2015, e a representação simbólica da cor preta para a cultura ocidental, relacionada ao luto, às coisas negativas, é possível afirmar que o livro representa a morte daquilo que era visto como essencial no início do filme.

Em todas essas sequências o que fica mais visível ao primeiro olhar do leitor/ espectador é o "essencial". De acordo com Vieira (2015), esse recurso é chamado de 
saliência, a partir do elemento que chama a atenção do leitor/espectador é possível fazer associações como outros componentes da organização textual, corroborando para a sintaxe visual. Nesse sentido, o "essencial" vai sendo associado a outras imagens ao longo da narrativa fílmica.

A seguir, selecionamos uma Sequência que retrata como essa associação pode ocorrer.

Quadro 4: Categorias para a análise de imagens em movimento.

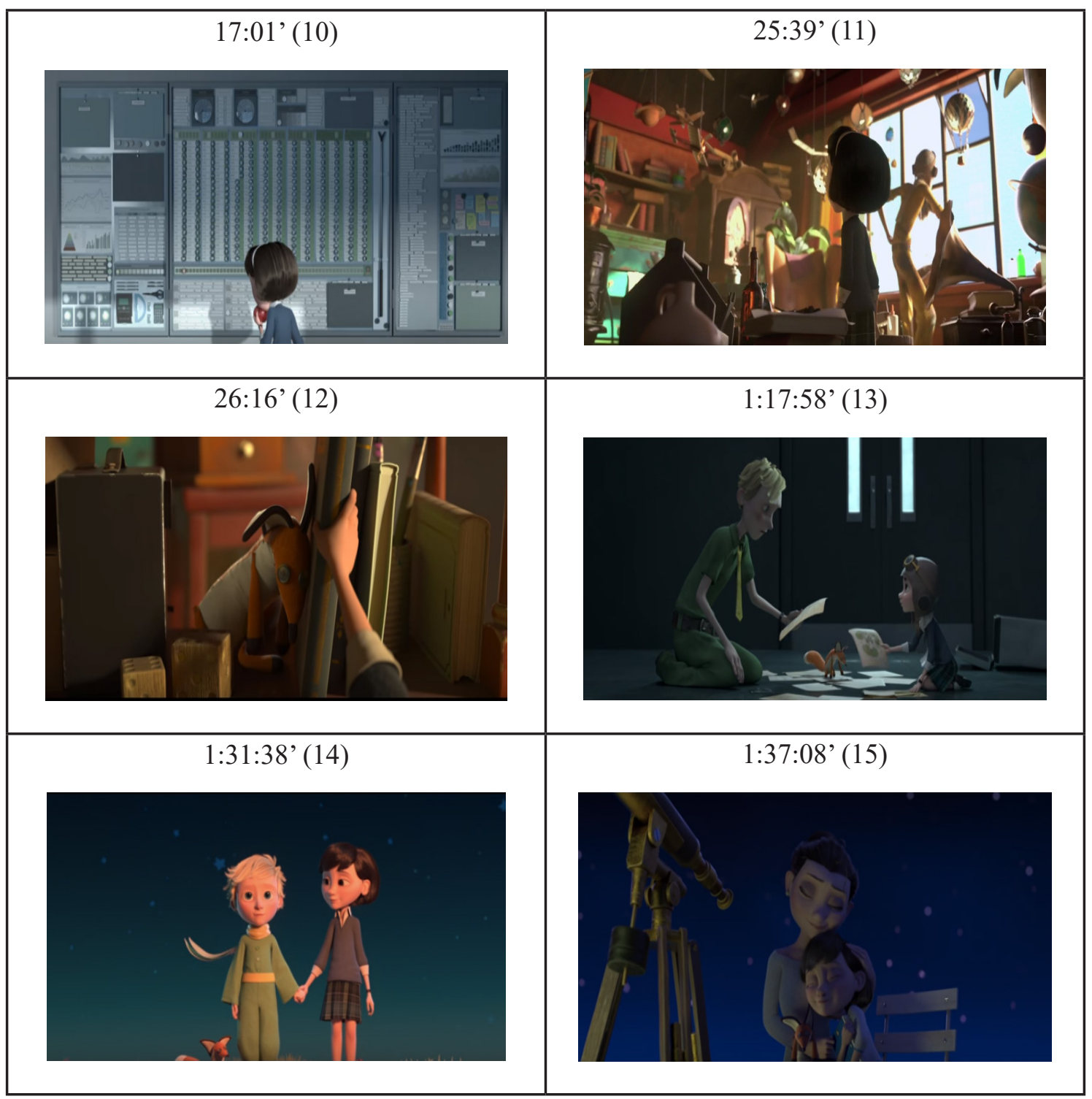

Fonte: Adaptação cinematográfica O Pequeno Príncipe (2015). 
Ao longo de todo o texto cinematográfico, a construção do sentido daquilo que é essencial vai sofrendo alterações, isto é, no início da adaptação o essencial é o plano de vida da menina, criado pela mãe, o que implicaria em uma formação acadêmica reconhecida e colocação no mercado de trabalho, esse signo aparecem em primeiro plano na Sequência (10).

À medida em que a história se desdobra, outros elementos aparecem em primeiro plano, representando aquilo que se torna essencial para a personagem protagonista. Ao associar essa Sequência ao texto verbal de Exupéry, também se pode perceber que as imagens o representam, como segue nos recortes abaixo:

Quadro 5: Recortes da obra literária $O$ Pequeno Príncipe.

"Se lhes dou esses detalhes sobre o asteróide B 612 e lhes confio o seu número, é por causa das pessoas grandes. As pessoas grandes adoram os números. Quando a gente lhes fala de um novo amigo, elas jamais se informam do essencial. Não perguntam nunca: "Qual é o som da sua voz? Quais os brinquedos que prefere? Será que coleciona borboletas?" Mas perguntam: "Qual é sua idade? Quantos irmãos ele tem? Quanto pesa? Quanto ganha seu pai?" Somente então é que elas julgam conhecê-lo" (p. 19).

““"Era uma vez um pequeno príncipe que habitava um planeta pouco maior que ele, e que tinha necessidade de um amigo..." Para aqueles que compreendem a vida, isto pareceria sem dúvida muito mais verdadeiro" (p. 20).

"Há milhões e milhões de anos que as flores fabricam espinhos. Há milhões e milhões de anos que os carneiros as comem, apesar de tudo. E não será sério procurar compreender por que perdem tanto tempo fabricando espinhos inúteis? Não terá importância a guerra dos carneiros e das flores? Não será mais importante que as contas do tal sujeito?” (p. 29).

"Eis o meu segredo. É muito simples: só se vê bem com o coração. O essencial é invisível para os olhos" (p. 72).

“As estrelas são belas por causa de uma flor que não se vê...” (p. 77).

“o que eu vejo não é mais que uma casca. O mais importante é invisível...” (p. 78).

Fonte: O Pequeno Príncipe (2015).

Os textos selecionados no Quadro 4 vão ao encontro daquilo que Exupéry possivelmente destaca como essencial em sua obra, isto é, o essencial para esse autor não são as coisas materiais, as conquistas numéricas e sim as relações pessoais de amizade e afeto, que tornam as pessoas seres melhores, coisas que são invisíveis aos olhos. Nesse sentido, podemos afirmar que a Sequência selecionada no Quadro 3 representa 
esse sentimento, à medida em que o "essencial" na Sequência (10) corrobora para a associação com os discursos das páginas 19 e 29 da obra literária.

Do mesmo modo, a página 20 do texto verbal pode ser associado à representação imagética das Cenas (12) e (14). O discurso da página 72 é sem dúvida o que representa toda a Sequência selecionada.

É claro que está é uma entre várias possibilidades de associações. O que quisemos mostrar aqui é como as associações dentro da própria construção da narrativa cinematográfica e entre o texto visual e o texto verbal das duas obras é possível.

Retomando a definição do conceito de metafunção composicional, conforme definem Kress e van Leeuwen (2006, p. 181), buscamos também compreender como a organização textual - verbal e visual - na obra literária de Exupéry confere ao seu texto valores e sentidos específicos. Além disso, trazemos para a guisa dessa análise o conceito de metafunção representacional, já que consideramos que os processos simbólicos que compõem os trechos que serão analisados são relevantes para a constituição dos sentidos.

De acordo com Kress e van Leeuwen (2006, p. 79), o atributo simbólico tem como principal característica a presença de elementos colocados em primeiro plano e busca representar "os participantes em termos de sua essência". Assim, tomamos como base esses dois conceitos - metafunção composicional e metafunção representacional para pensar nos recursos utilizados por Exupéry em sua obra e os sentidos que podem ser produzidos a partir do valor de informação e da saliência nos trechos selecionados e apresentados nos Anexos I e II desse artigo.

Ao considerar o valor de informação nas páginas 16 e 17 da obra literária (Anexo I), o que se tem é o texto verbal à esquerda, portanto aquilo que, conforme apontam Kress e van Leeuwen (2006), já está Dado ao leitor, e à direita a ilustração da personagem pequeno príncipe com a legenda "O principezinho sobre o asteroide B 612", isto é, o elemento Novo, aquilo que o leitor ainda não conhece. Nesse sentido, a organização textual das páginas 16 e 17 confirma a teoria de Kress e van Leeuwen (2006), uma vez que no texto verbal o autor dá continuidade a uma narrativa que o leitor já vem acompanhando e o texto não-verbal apresenta ao leitor aquilo que é também desconhecido do narrador e que só lhes será apresentado na página seguinte.

Ainda, como apontam os autores, na organização vertical da imagem, na parte superior aparecem os elementos apresentados como Ideais, aqueles que chamam a atenção do leitor e provocam suas emoções. Em contrapartida, na parte inferior localizam-se os elementos Reais, ou informativos, o que se comprova na ilustração de Exupéry, já que o texto verbal cria uma expectativa em relação ao pequeno planeta em que vive o pequeno 
príncipe enquanto o texto não-verbal revela ao leitor a imagem que ele busca conhecer e a legenda na parte inferior traz uma informação prática sobre o nome do asteroide.

Já no texto presente na página 26 (Anexo II), a organização textual é outra. O que se vê é uma composição em que o texto verbal ocupa uma posição Central, representando, então, o núcleo da informação, enquanto o texto imagético, que representa o planeta do pequeno príncipe, localiza-se à margem e é apresentado, portanto, como marginal. Isso significa dizer que nesse trecho o que importa não é onde o pequeno príncipe vive, mas sim o que ele sente. Assim, mais uma vez retomo aquilo que acredito mover a obra de Exupéry: a ideia do que é essencial. A ilustração do pequeno príncipe retratado em seu cotidiano, por sua vez, é posta na parte superior da página, o que possivelmente tende a provocar as emoções do leitor.

Outro recurso utilizado na estrutura composicional é a saliência, que tem por finalidade criar uma "hierarquia de importância entre os elementos", conforme apontam Kress e van Leeuwen (2006, p. 212). Esse recurso coloca em primeiro plano aquilo que deve ser mais importante para que o leitor faça associações secundárias e dê sentido ao que lê. Assim, o que se percebe nos dois recortes selecionados é que a personagem é o elemento colocado em saliência, o que nos permite observar que é a partir dele que o leitor deve fazer inferências externas e até mesmo colocar-se em outro lugar para conhecer as experiências vividas pela personagem.

Retomamos, desse modo, o que Kress e van Leeuwen (2006) afirmam sobre os processos simbólicos, isto é, o fato de que os elementos que são colocados em primeiro plano têm relação direta com os valores simbólicos que o autor deseja evidenciar. Kress e van Leeuwen (2006) asseveram que os seres humanos são capazes de modalizar sentidos ou mesmo de potencializa-los de acordo com seu contexto social e cultural. Assim, sabendo que os valores simbólicos são constituídos culturalmente, consideramos que ao expor em primeiro plano determinados elementos, Exupéry pretende projetar em seu leitor valores que acredita serem essenciais.

Conforme aponta Vieira (2015), a linguagem verbal escrita contribui para a representação de um quadro mais amplo em relação ao sistema semiótico visual, uma vez que a descrição das ações no sistema verbal é mais alargada ao contrário das imagens que tendem a simplificar os processos. Nesse sentido, fica claro que os recursos semióticos usados na construção da narrativa fílmica representam e reafirmam o discurso verbal que conduz a obra literária $O$ Pequeno Príncipe, corroborando para a coerência na construção das narrativas. 


\section{CONSIDERAÇÕES FINAIS}

O Pequeno Príncipe segue uma tendência do mercado cinematográfico que tem por objetivo atrair a audiência ao abordar o mesmo conteúdo de maneira diferente em mídias distintas. No entanto, não se pode negar que ao adaptar um best seller da literatura para o cinema, o novo texto chama a atenção de um olhar mais crítico do leitor. É nesse sentido que trabalhos que abordem o texto multimodal contribuem para desenvolver no leitor a interpretação de textos multimodais e de como seus recursos semióticos são articulados para construir determinados significados. A partir desse conhecimento, o leitor torna-se consciente das escolhas que subjazem textos multimodais e ele pode passar atribuir novos significados àquilo que lê.

Assim, tanto a Gramática Visual (KRESS; VAN LEEUWEN, 2006) quanto estudos que a tomam por base para a análise de textos verbais e visuais fornecem um rico aporte para a análise e interpretação de textos multimodais, conforme buscou-se demonstrar com o presente estudo. Desse modo, analisando a obra literária (escrita) e a cinematográfica (imagética) foi possível verificar as particularidades do processo de construção dos elementos no filme e suas implicações para a formação dos sentidos. Diante disso, podemos afirmar que Osborne, em sua adaptação, usa recursos multimodais com a finalidade de fazer com seu espectador relacione características evidenciadas no texto imagético às que são apresentadas por Exupéry na obra literária, e compreenda aquilo que vê com base nos discursos tanto verbais quanto visuais que são colocados à sua disposição.

A partir das análises aqui realizadas, fica evidente a importância do estudo multimodal na vida cotidiana, mais do que isso, fica claro que as imagens, sons, cores e outros modos são mensagens estruturadas que representam sentidos. Assim, com os sistemas, modos e recursos semióticos usados na produção de um texto, o autor potencializa a criação de significados e de seus efeitos. Além disso, com esse estudo foi possível confirmar que o significado não está no objeto, pessoa ou palavra, mas que é o sujeito leitor/espectador quem constrói os sentidos através dos sistemas de representação que é fixado pelos diversos sistemas semióticos.

Embora o trabalho com textos cinematográficos, na maioria das vezes, deixe à margem a análise de outros sistemas semióticos como áudio e efeitos sonoros, em razão de ser analisado como um texto estático, acredito que o presente artigo alcançou o seu objetivo principal: mostrar como as múltiplas semioses se articulam na sintaxe visual estabelecendo coerência na construção das narrativas. Desse modo, é importante 
observar que a ideia de que a linguagem visual em sentido lato, tanto como processo ou como produto, tem potencialidades e suas várias expressões e articulações precisam de maiores investigações.

\section{REFERÊNCIAS}

ALMEIDA, D. B. pelos caminhos do letramento visual: por uma proposta multimodal de leitura crítica de imagens. In: Linguagem em Foco - Revista do Programa de PósGraduação em Linguística Aplicada da UECE/ Universidade Estadual do Ceará. v.3. n. 5. Fortaleza: EdUECE, 2012, p. 43-63. Disponível em: http://www.uece.br/ linguagememfoco/dmdocuments/Linguagem\%20em\%20Foco\%202011_2.pdf. Acesso em: 27/01/2019.

BACHI, L. R. G. Uma análise textual de o Pequeno Príncipe: as visões sobre a infância no livro de Saint-Exupéry e no filme de Osborne. Orientador: Edson Carlos Romualdo. Dissertação (Mestrado) - Universidade Estadual de Maringá, Centro de Ciências Humanas, Letras e Artes, Departamento de Teorias Linguísticas e Literárias, Programa de Pós-Graduação em Letras, 2020.

CARVALHO, F.F. Semiótica Social e Gramática Visual: o sistema de significados interativos.In: Revista Anglo Saxonica, Ser: III n.12010, p. 263-281.Disponível em: http:// repositorio.ul.pt/bitstream/10451/5589/1/0873-0628_2010-001-000_00263-00281.pdf. Acesso em: 01/02/2019.

EXUPÉRY, A. S. O Pequeno Príncipe. Trad: Dom Marcos Barbosa. 49. ed. Rio de Janeiro: Aguiar, 2015.

HALLIDAY, M.A.K; MATTHIESSEN, C. M. I. M. An introduction to functional grammar. 3rd ed. London: Routledge, 2004.

HENDGES, G. R.; NASCIMENTO, R. G. Convergências e desafios para a pesquisa com imagens em movimento sob a perspectiva da análise do discurso multimodal. In: Letras, Santa Maria, v. 26, n. 52, p. 25-47, jan./jun. 2016, p. 25-47.

HOLANDA, E. F. A multimodalidade: a imagem como composição em interchange intro. In: Linguagem em Foco - Revista do Programa de Pós-Graduação em Linguística Aplicada da UECE/ Universidade Estadual do Ceará. v.3. n. 5. Fortaleza: EdUECE, 2012, p. 129-144. Disponível em: http://www.uece.br/linguagememfoco/dmdocuments/ Linguagem\%20em\%20Foco\%202011_2.pdf. Acesso em: 27/01/2019. 
IEDEMA, R. Analysing film and television: a social semiotic account of hospital: an unhealthy business. In: van LEEUWEN, T. JEWITT, C. (Eds.). Handbook of visual analysis. London: Sage, 2001. p. 101-204.

IEDEMA, R. Multimodality, resemiotization: extending the analysis of discourse as multi-semiotic practice. In: Visual Communication, Vol. 2(1): 29-57, 2003.

KRESS, G. VAN LEEUWEN. Reading images: the grammar of visual design. London; New York: Routledge, 2006.

KRESS, G. Literacy in the New Media. London: Routledge, 2003.

KRESS, G. Writing the future: English and the Making of a Culture of Innovation. London: Routledge, 1995.

MORAES, G. L. Do livro ilustrado ao aplicativo: reflexões sobre multimodalidade na literatura para crianças. In: Estudos de literatura brasileira contemporânea, n. 46, p. 231-253, jul./dez. 2015. Disponível em: file://C:/Users/lilia/Downloads/Dialnet-DoLivr ollustradoAoAplicativo-5152485.pdf. Acesso em: 31/01/2019.

O'HALLORAN, K. (ed.) Multimodal discourse analysis: systemic functional perspectives. London: Continuum, 2004.

PLAZA, J. Tradução intersemiótica. São Paulo: Perspectiva, 2008. Reimpressão.

SANTOS, H. G. V. Do texto à tela: o papel dos mecanismos de construção de sentido na obra "O auto da compadecida". Trabalho de Conclusão de Curso Graduação em Letras. Universidade Estadual da Paraíba, Centro de Humanidades, 2016. Disponível em: $\quad$ http://dspace.bc.uepb.edu.br/jspui/bitstream/123456789/12375/1/PDF\%20-\%20 Kahlil\%20Gibran\%20Vieira\%20dos\%20Santos.pdf. Acesso em: 19/01/2019.

SIERAKOWSKI, A. P. C. Literatura de massa e formação do leitor: o letramento de receptores da saga crepúsculo do papel às telas. Maringá: [s.n.], 2012, p. 50-60. Disponível em: http://www.ple.uem.br/defesas/pdf/apcsierakowski.pdf. Acesso em: 05/02/2019.

STAM, R. Beyond fidelity: the dialogics of adaptation. NAREMORE, J. (Org.) Film adaptation. New Jersey, Rutgers University Press, 2000. 
VIEIRA, J. Introdução à Multimodalidade: Contribuições da Gramática SistêmicoFuncional, Análise de Discurso Crítica, Semiótica Social. Josenia Vieira e Carminda Silvestre. - Brasília, DF: J. Antunes Vieira, 2015.

O Pequeno Príncipe Filme. Direção: OSBORNE, M. Produção de Alexis Vonarb; Aton Soumache; Dimitri Rassam. Canadá: Paris Filmes, 2015. Disponível na plataforma Netflix. 


\section{ANEXO I}
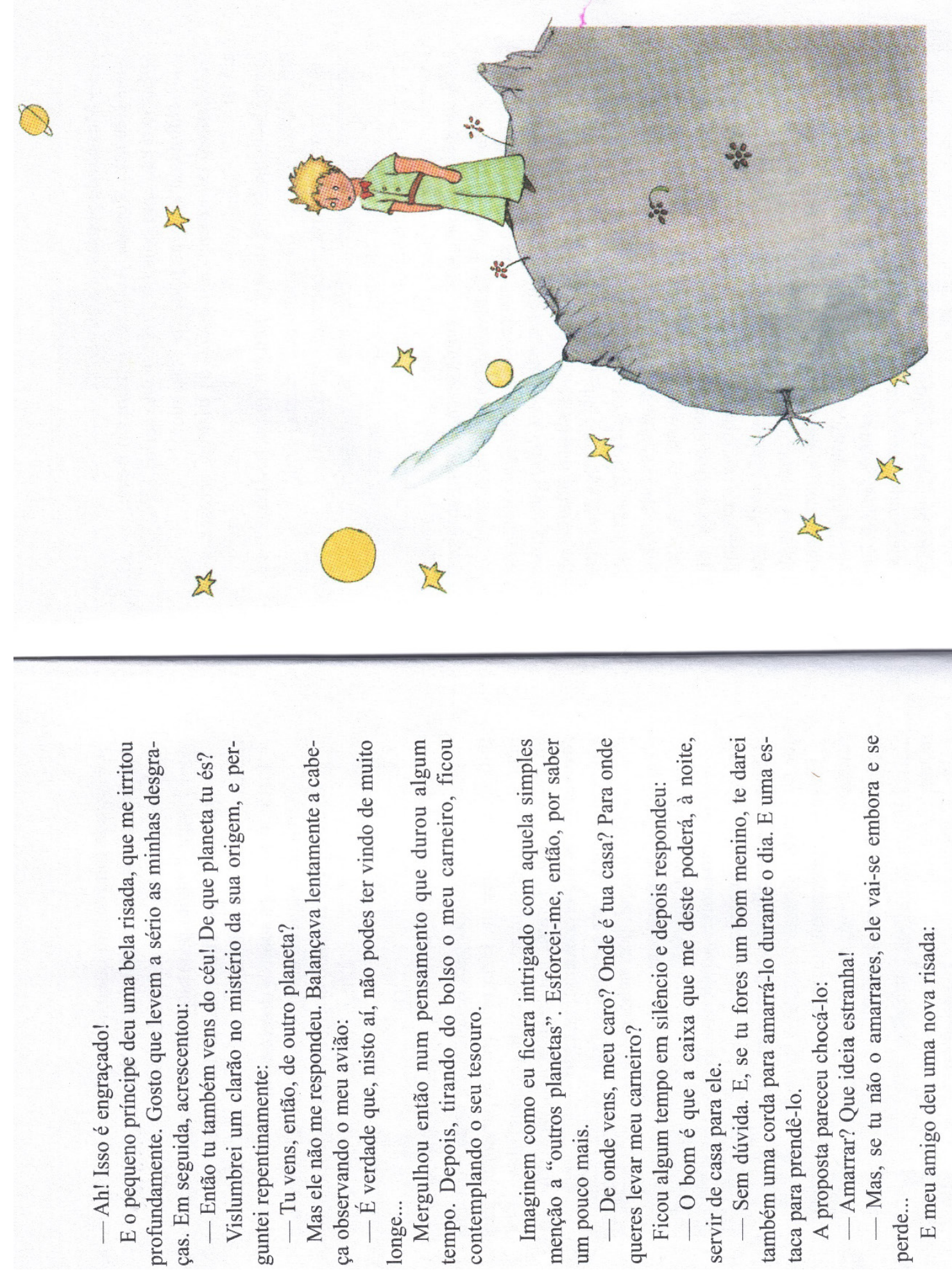


\section{ANEXO II ${ }^{2}$}

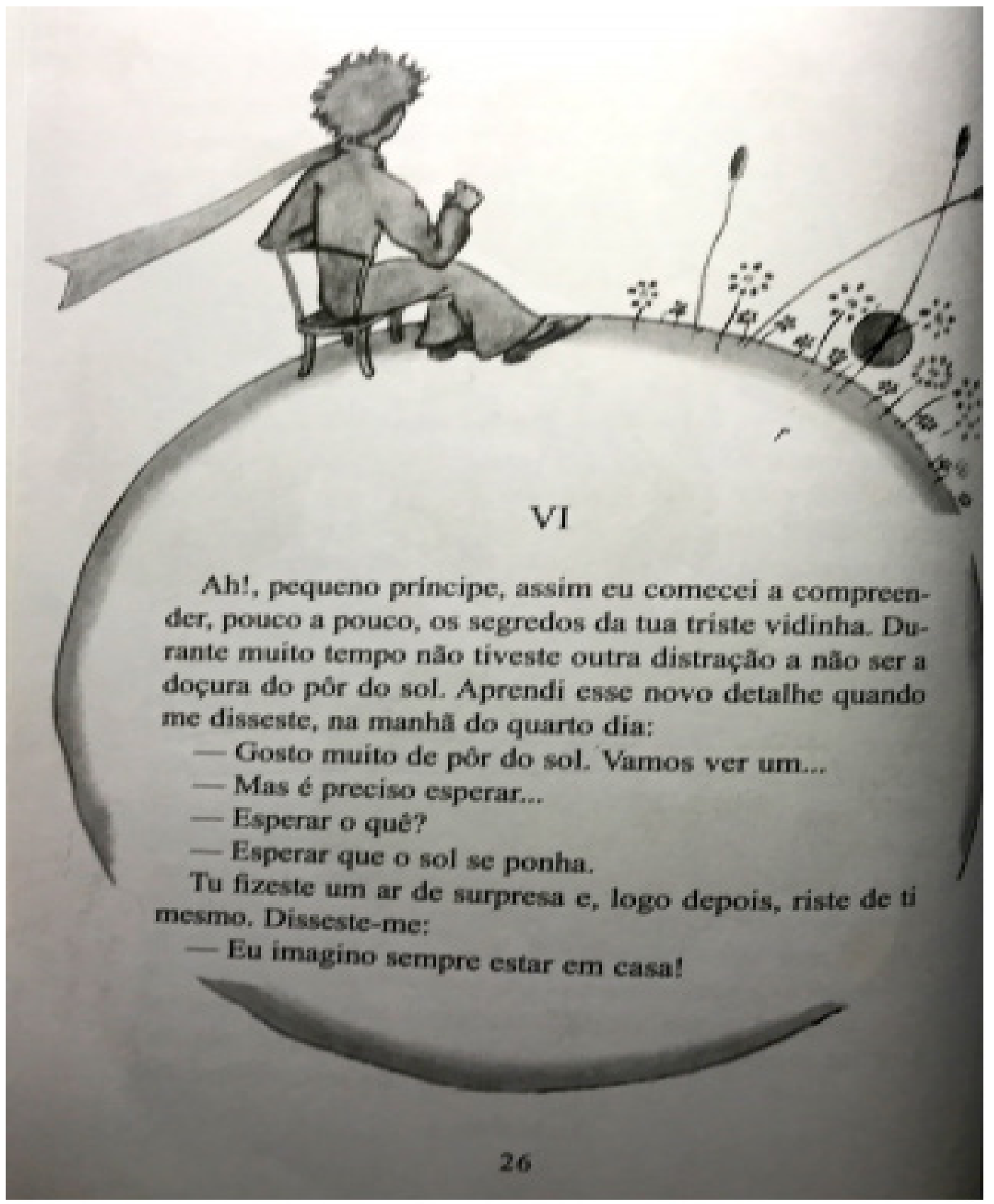

Recebido em: 29 jul. 2021. Aceito em: 28 set. 2021.

${ }^{2}$ As imagens usadas nos Anexos I e II são de direito público e foram retiradas da obra literária O Pequeno Príncipe editada pela editora Agir em 2015. A reprodução das imagens neste artigo atende a fins de pesquisa e não deve ser comercializada ou visar a fins lucrativos. 